\title{
Ensayo Pictórico: Imágenes en trasplante de páncreas: ¿Qué debemos buscar?
}

Francisca Leiter $\mathrm{H}^{1,2}{ }^{\star}$, Rosario Valdés 0..,2, Eduardo Siña Z., ${ }^{1,2}$, Yessenia Orellana A.,2, Andrea Glasinoic P.1,2, Javier Chapochnick $F^{3}$

1. Departamento de Radiología, Clínica Santa María. Santiago-Chile.

2. Universidad de los Andes. Santiago-Chile.

3. Departamento de Cirugía, Jefe de programa de trasplante de páncreas e hígado, Clinica Santa María. Santiago-Chile.

Pictorial Essay: Imaging in pancreas transplants: What should we look for?

Abstract. Pancreas transplantation is a therapeutic alternative for diabetic patients with severe metabolic complications and/or terminal chronic kidney disease. In $80 \%$ of cases, a simultaneous transplant of pancreas and kidney is performed.

Ultrasound (US) is the technique of choice for a first evaluation of the implant, mainly the spectral Doppler mode, which allows evaluation of the graft vasculature and perfusion. Computed tomography (CT) and magnetic resonance imaging (MRI) are reserved for the evaluation of complications (Table).

A retrospective review of a series of cases of pancreas-kidney transplantation performed at our institution between 2014 and 2017 was carried out, with a total of 12 cases.

Keywords: Pancreas transplantation, Chronic kidney disease, Spectral Doppler.

Resumen. El trasplante de páncreas es una alternativa terapéutica para pacientes diabéticos con complicaciones metabólicas severas y/o enfermedad renal crónica terminal. En el $80 \%$ de los casos, se realiza trasplante simultáneo de páncreas y riñón.

El ultrasonido (US) es la técnica de elección para una primera evaluación del injerto, principalmente el modo Doppler espectral. Este último permite la evaluación de la vasculatura y perfusión de injerto. La tomografía computada (TC) y resonancia magnética (RM) se reservan para la evaluación de complicaciones (Tabla). Se realizó una revisión retrospectiva de una serie casos de trasplante páncreas-riñón realizada en nuestra institución entre los años 2014 y 2017, con un total de 12 casos.

Palabras clave: Trasplante de páncreas, Enfermedad renal crónica, Doppler espectral.

Leiter F., et al. Imágenes en trasplante de páncreas: Que debemos buscar. Rev Chil Radiol 2018; 24(1): 34- 39.

Correspondencia: Francisca Leitier / francisca.leitier@gmail.com

Trabajo enviado el 26 de marzo de 2018. Aceptado para publicación el 24 de abril de 2018.

\section{Objetivos}

1. Exponer una serie de casos de trasplante páncreas-riñón realizados en nuestra institución entre los años 2014 y 2017.

2. Describir los hallazgos ecográficos normales en el injerto pancreático, haciendo énfasis en los parámetros claves a evaluar por esta técnica.

3. Realizar una revisión pictográfica de los hallazgos imagenológicos presentes en algunas de las complicaciones pancreáticas postoperatorias. 


\section{Marco teórico}

El trasplante de páncreas es una alternativa terapéutica para pacientes diabéticos con complicaciones metabólicas severas y/o enfermedad renal crónica terminal. En el $80 \%$ de los casos, se realiza trasplante simultáneo de páncreas y riñón.

El ultrasonido (US) es la técnica de elección para una primera evaluación del injerto, principalmente el modo Doppler espectral. Este último permite la evaluación de la vasculatura y perfusión de injer- to. La tomografía computada (TC) y resonancia magnética $(\mathrm{RM})$ se reservan para la evaluación de complicaciones (Tabla).

Se realizó una revisión retrospectiva de una serie casos de trasplante páncreas-riñón realizadas en nuestra institución entre los años 2014 y 2017, con un total de 12 casos. Presentamos una revisión pictográfica de los hallazgos normales 0 esperables en la evaluación post-operatoria del injerto y de algunas de las complicaciones.

Tabla. Complicaciones trasplante páncreas

\section{Tempranas}

- Pancreatis aguda*

- Fístulas

- Infección y abscesos

- Trombosis vascular*

- Hemorragia postquirúrgica*

- Colecciones peri-injerto*

- Dehiscencia anastomótica

\section{Tardías}

- Rechazo del injerto

- Formación de pseudoquistes

- Enfermedad linfoproliferativa post trasplante

- Obstrucción intestinal*

- Infecciones colónicas

- Pseudoaneurismas

* Corresponden a las complicaciones observadas en nuestra serie de casos.

\section{Descripción de la técnica quirúrgica ${ }^{1,2}$}

- Anastomosis digestiva: El injerto incluye el segmento de duodeno del donante adherida a la cabeza del páncreas ("asa en C"). Este último (D), es anastomosado con un asa de yeyuno del receptor (Ye).

- Irrigación arterial: Anastomosis en "Y" utilizando la arteria ilíaca común del donante $(\mathrm{Y})$. Se realiza una anastomosis termino-terminal de las ramas interna y externa de esta última, con las arterias mesentérica superior (AMS) y esplénica (AE) del donante. Posteriormente se une la anastomosis en "Y" con la arteria ilíaca común derecha del receptor (Figura 1).

- Drenaje venoso: la vena porta del donante (VP) se anastomosa con la $\mathrm{VCl}$ (más frecuente), vena ilíaca o vena mesentérica superior del receptor.

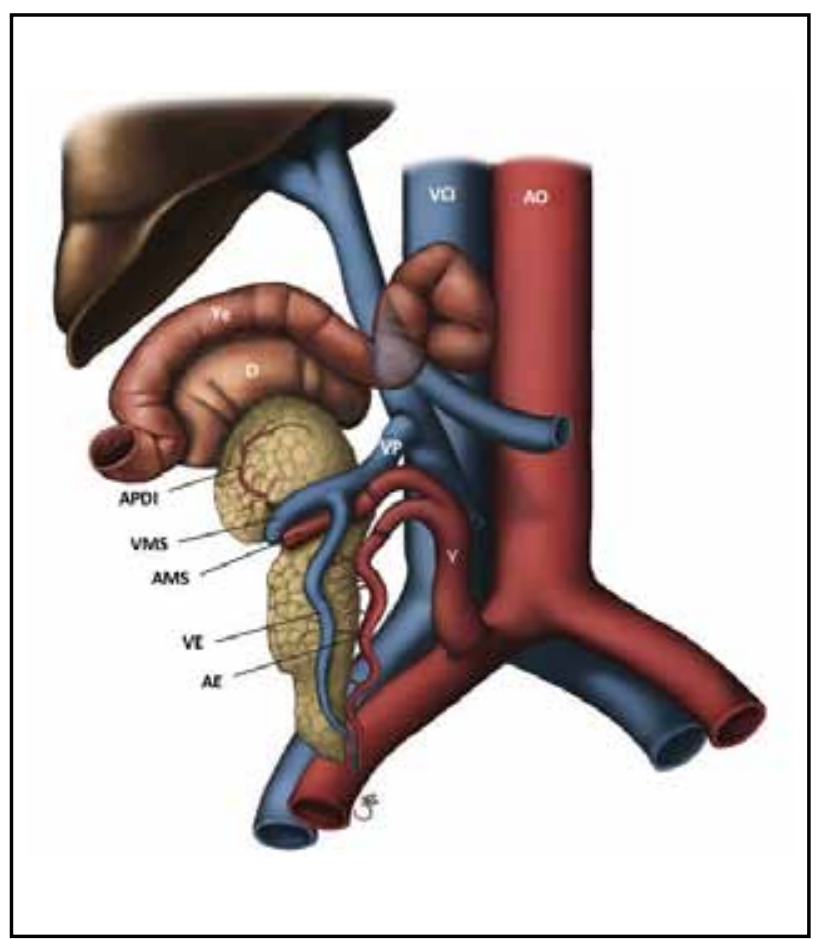

Figura 1. Técnica quirúrgica trasplante de páncreas. APDI: Arteria pancreato-duodenal inferior. VMS: Vena mesentérica superior. AMS: Arteria mesentérica superior. VP: Vena porta. VE: Vena esplénica. AE: Arteria esplénica. Y: Arteria ilíaca común del donante. D: Duodeno del donante. Ye: Yeyuno del receptor. AO: Aorta. VCI: Vena cava inferior. Radiology abril 2015; 275(1). 


\section{Evaluación imagenológica del injerto pancreático} Ecografía Doppler color y espectral",
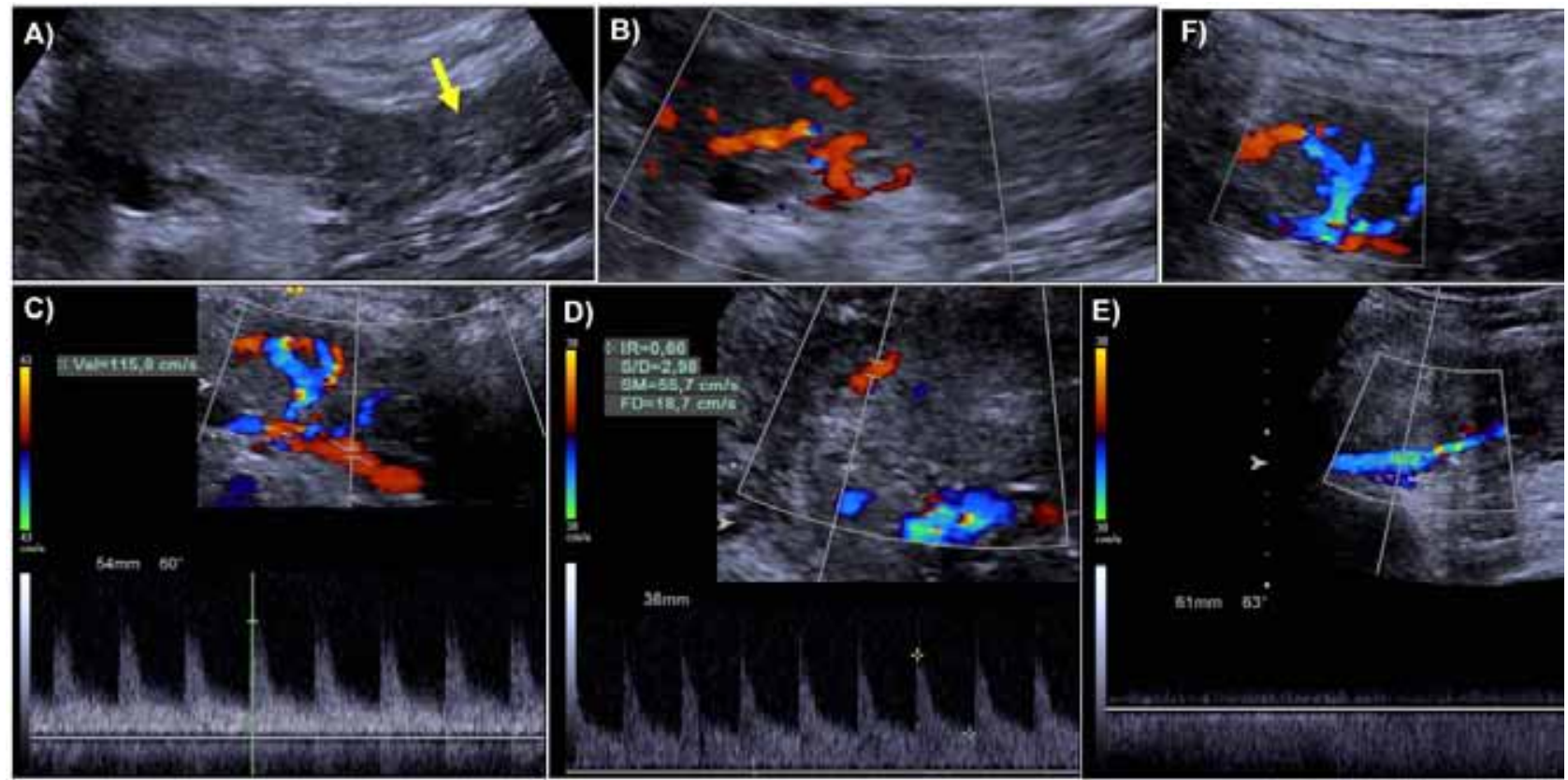

Figura 2. Ecografía Doppler color y espectral ${ }^{1,3}$ Parénquima hipoecogénico homogéneo (Figuras 2A - 2B). Conducto pancreático principal de diámetro normal (flecha). • Anastomosis arterial en "Y": Se debe evaluar idealmente la arteria mesentérica superior AMS, esplénica y vasos intrapancreáticos. Debemos observar la morfología de la curva y la presencia de flujo diastólico anterógrado continuo (Figura 2C), con IR entre 0,5 - 0,7 (Figura 2D). Doppler vena porta: Curva monofásica. En etapas precoses es frecuente observar aplanamiento de la curva en el sitio de anastomosis venosa, secundario a un menor calibre del vaso a éste nivel (Figuras $2 \mathrm{E}-2 \mathrm{~F})$.

\section{Tomografía computada con contraste - Técnica trifásica.}

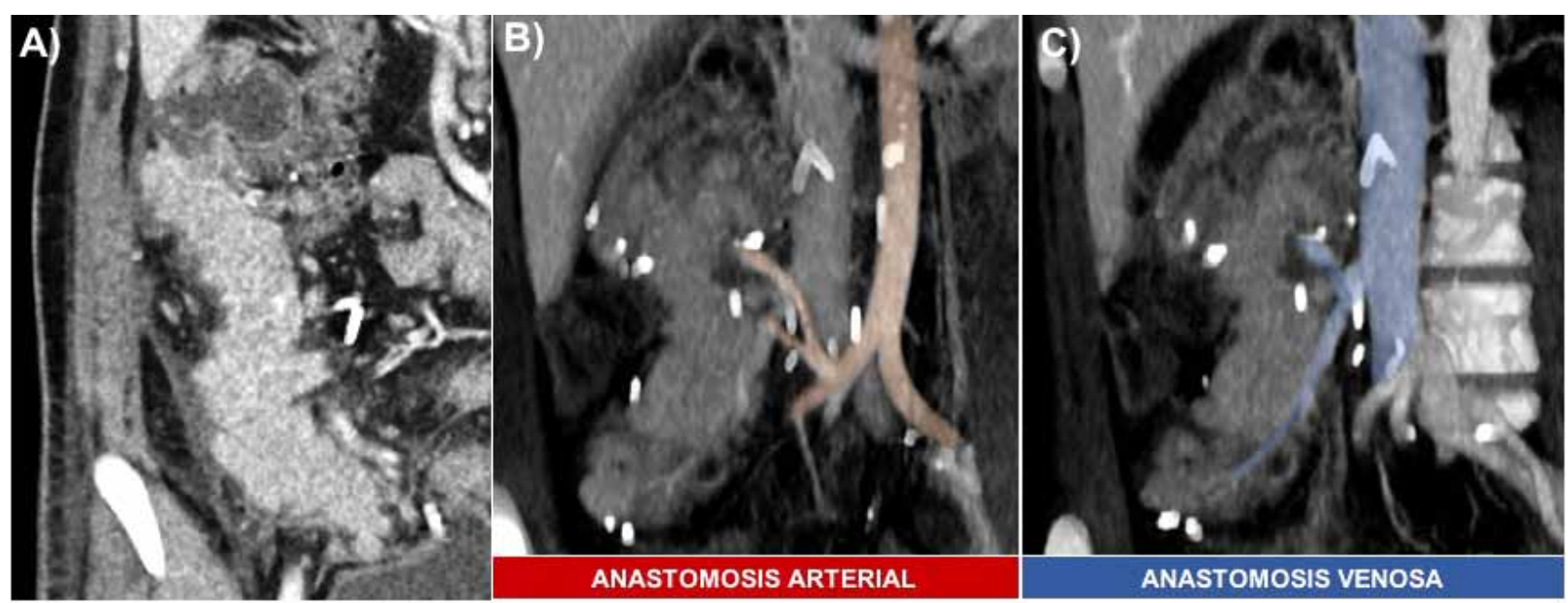

Figura 3. Hallazgos normales en TC de abdomen y pelvis con contrasten fases arterial (B) y portovenosa (A, C). Se observa realce homogéneo del injerto, principalmente en fase arterial (Figura 3A). Las anastomosis arteriales (Figura $3 \mathrm{~B}$ ) y venosas (Figura $3 \mathrm{C}$ ) deben ser permeables. Las imágenes sin contraste permiten diferenciar un hematoma peri-injerto de un pseudoaneurisma arterial, cuando se comparar con las imágenes post-contraste. 


\section{Pancreatitis aguda del injerto}
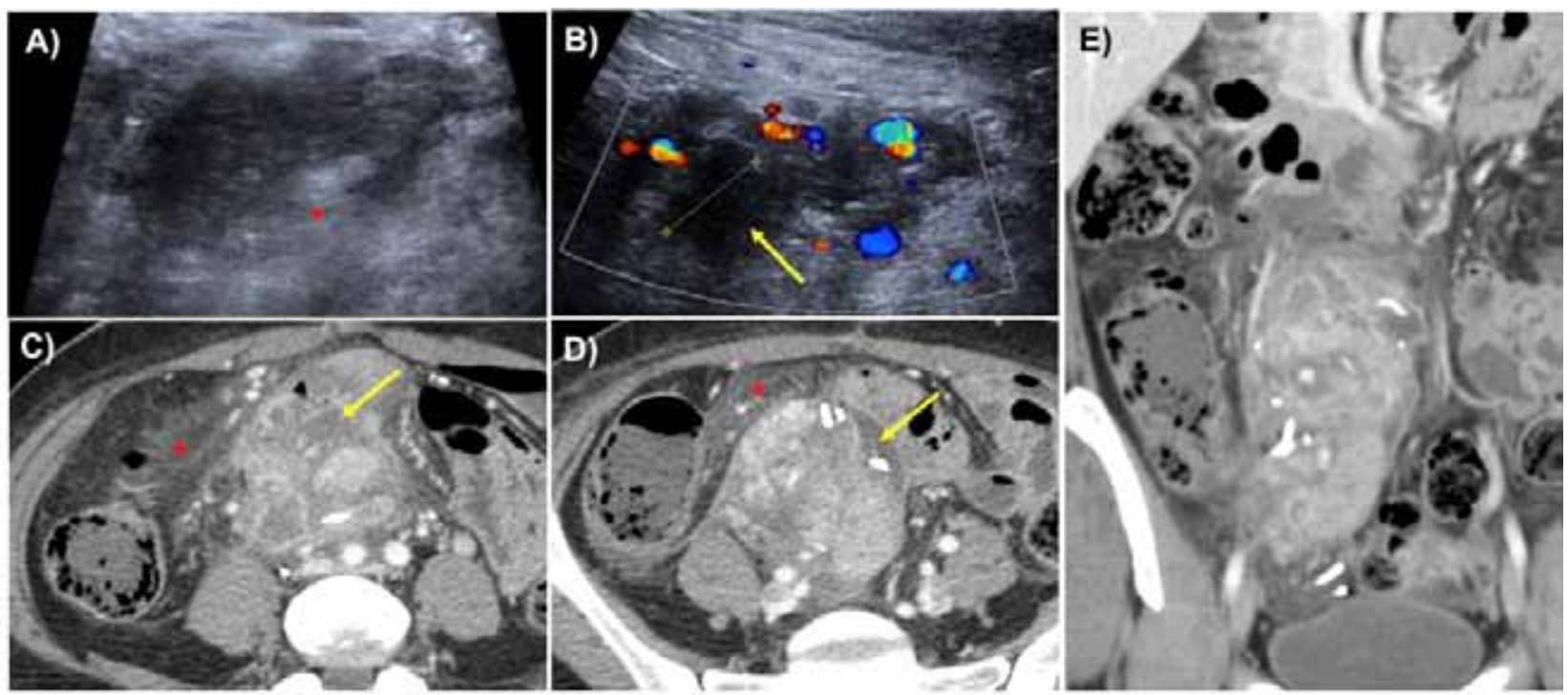

Figura 4. Pancreatitis aguda del injerto. Mujer de 47 años, consulta por fiebre y dolor abdominal. En las imágenes de US (Figuras 4A4B) se observa el injerto pancreático voluminoso y disminuido de ecogenicidad en forma heterogénea (A). En las imágenes seleccionadas de TC (Figuras 4C-4D-4E), se observa aumento difuso del tamaño del injerto y realce heterogéneo, asociado a cambios inflamatorios del tejido adiposo adyacente $\left.{ }^{*}\right)$. Además, líquido peri-pancreático (flechas).

\section{Trombosis arterial y venosa}
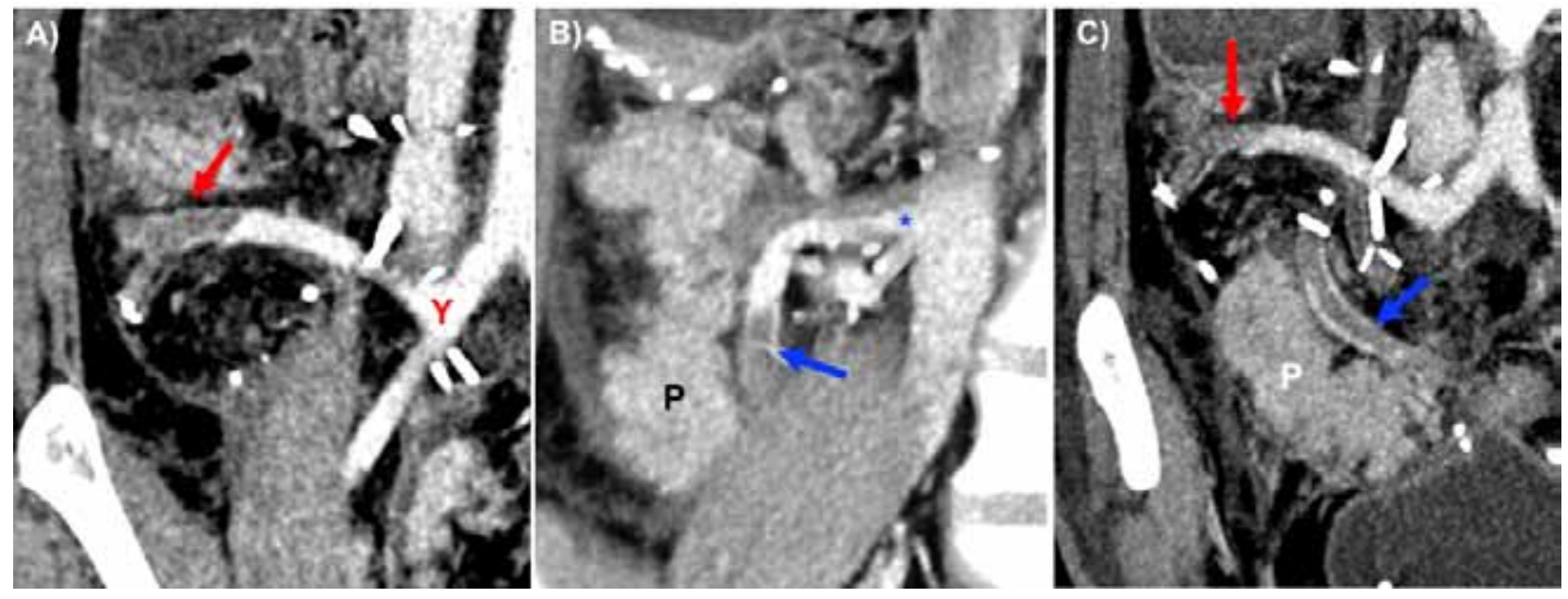

Figura 5. Trombosis arterial venosa. Hombre de 37 años cursando su $8^{\circ}$ día post trasplante. Evoluciona con fiebre. En las imágenes seleccionadas de TC, se observa trombosis del segmento más distal de la arteria mesentérica superior Pancreatitis aguda del injerto Mujer de 47 años, consulta por fiebre y dolor abdominal. En las imágenes de US (Figuras 4A4B) se observa el injerto pancreático voluminoso y disminuido de ecogenicidad en forma heterogénea (Figuras $5 \mathrm{~A}-\mathrm{C}$ ), así como también de la vena esplénica en prácticamente toda su extensión (Figuras 5B-5C). El injerto pancreático no mostraba alteraciones en su realce.

Y: Anastomosis A. llíaca común donante A. llíaca común derecha receptor. * Anastomosis vena porta donante - VCS receptor. P: Injerto pancreático. 


\section{Obstrucción intestinal}

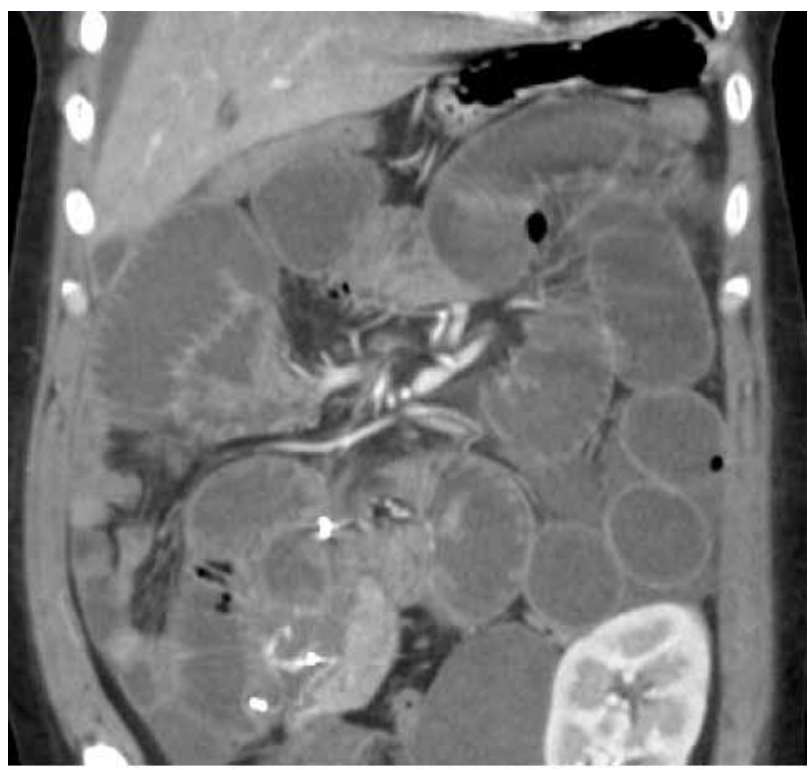

Figura 6. Obstrucción intestinal. Mujer de 45 años, con dolor y distensión abdominal. En la imagen se observa dilatación en rango patológico de asas de intestino delgado. La paciente Estenosis de la anastomosis venosa portal Mujer de 29 años, cursando su $1^{\underline{a}}$ día post trasplante de páncreas-riñón. En las imágenes de US (Figuras 8A y 8B), no se logra evaluar flujo de la vena porta. En la imagen de TC (C), se observa disminución fue sometida a intervención quirúrgica, confirmándose la presencia de una hernia interna en la raíz del mesenterio (Figura 6).

\section{Hemorragia de la anastomosis digestiva}
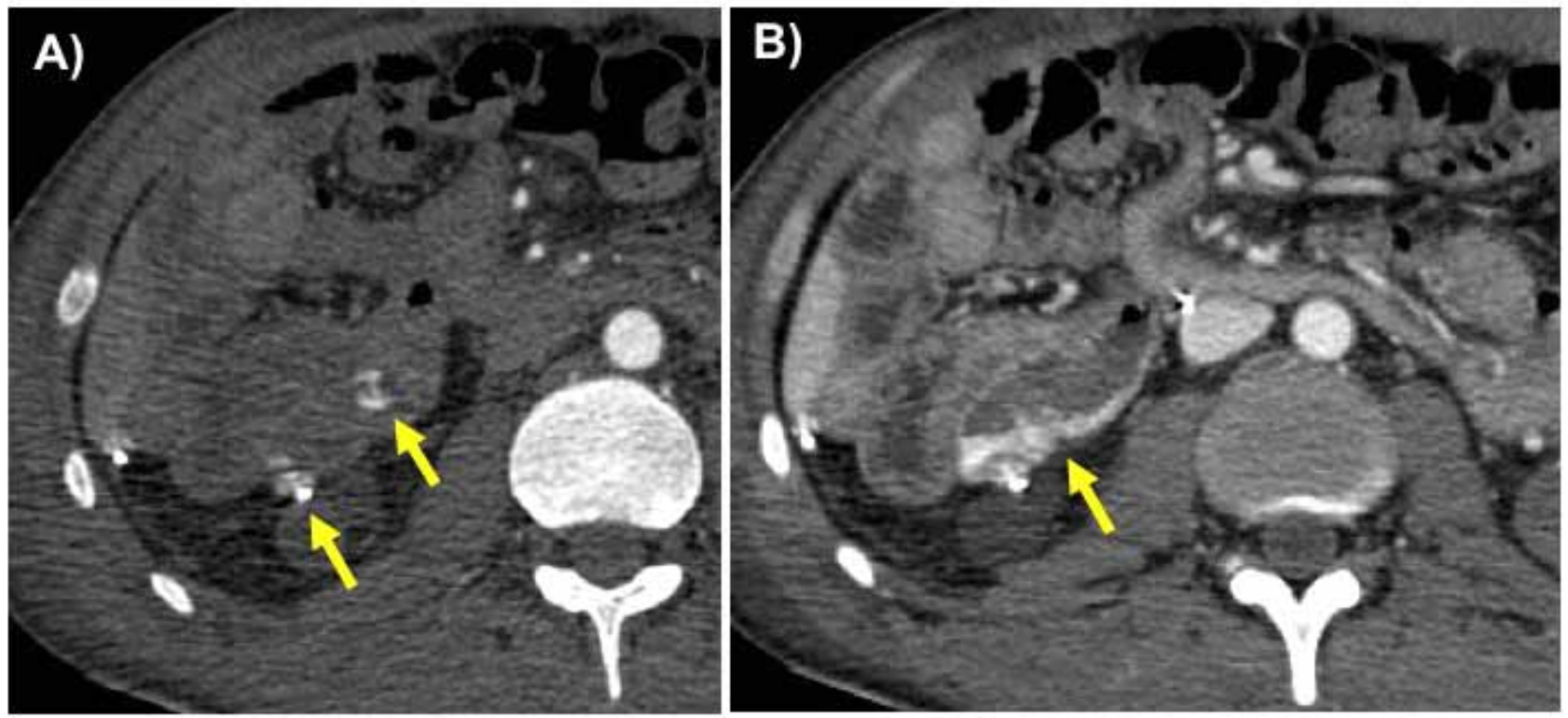

Figura 7. Hemorragia de la anastomosis digestiva. Hombre de 33 años, cursando el 6ª día post trasplante inicia dolor abdominal y caída de hematocrito. En las imágenes seleccionadas de TC con contraste, se observan signos compatibles con sangrado arterial adyacente a anastomosis duodeno-yeyunal (flechas). En la laparotomía exploradora se constata sangrado perianastomótico, por lo que se realiza hemostasia y refuerzo del sitio de anastomosis (Figura 7A y 7B). 


\section{Estenosis de la anastomosis venosa portal}

Mujer de 29 años, cursando su $1^{a}$ día post trasplante de páncreas-riñón. En las imágenes de US (Figuras $8 \mathrm{~A}$ y 8B), no se logra evaluar flujo de la vena porta. En la imagen de TC $(C)$, se observa disminución de calibre del puente venoso portal, adyacente a la anastomosis con la VCl (flecha) asociado a edema del tejido adyacente en contexto de cambios post quirúrgicos, sin embargo, esta se encuentra permeable y sin signos de trombosis (Figuras $8 \mathrm{~A}, 8 \mathrm{~B} \mathrm{y} 8 \mathrm{C}$ ).
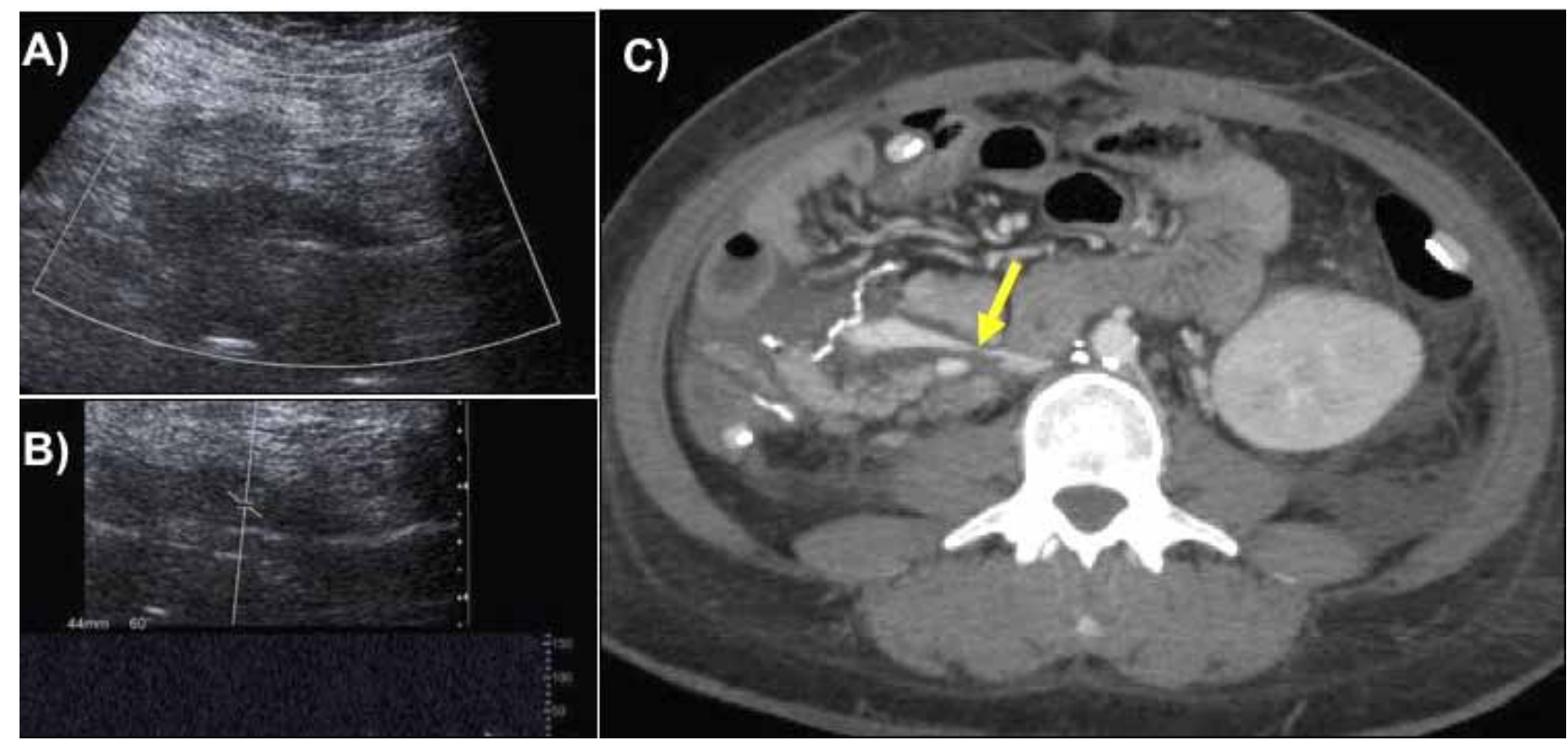

Figura 8. Estenosis de la anastomosis venosa-portal.

\section{Conclusiones}

El trasplante de páncreas es una alternativa terapéutica efectiva en pacientes diabéticos. La evaluación con imágenes del injerto requiere del conocimiento de las distintas técnicas quirúrgicas y eventuales complicaciones asociadas. Como primera técnica imagenológica se utiliza la ecotomografía Doppler, para la evaluación del injerto y su vascularización con las curvas de IR. La TC se reserva en caso de complicaciones.

\section{Referencias}

1. Vandermeer F, Manning M, Frazier A, Wong-YouCheong J. Imaging of Whole-Organ Pancreas Transplants. RadioGraphics 2012; 32: 411-435.

2. Tolat PP, Foley WD, Johnson C, Hohenwalter MD, Quiroz FA. Pancreas Transplant Imaging: How I Do It. Radiology 2015 April; 275(1): 14-27.

3. França M. et al. Imaging of Pancreas Transplantation and Its Complications. Insights into Imaging 2010; 1.5-6: 329-338. 